\title{
Treatment of COVID-19 by Controlling the Activity of the Nuclear Factor-Kappa B
}

\author{
Mahmoud Saad Mohamed Elkhodary \\ General Organization for Exporting and Importing Control, Suez, Egypt \\ Email: Surataljomaa@Gmail.com
}

How to cite this paper: Elkhodary, M.S.M. (2020) Treatment of COVID-19 by Controlling the Activity of the Nuclear Factor-Kappa B. CellBio, 9, 109-121. https://doi.org/10.4236/cellbio.2020.92006

Received: May 13, 2020

Accepted: June 2, 2020

Published: June 5, 2020

Copyright $\odot 2020$ by author(s) and Scientific Research Publishing Inc. This work is licensed under the Creative Commons Attribution International License (CC BY 4.0).

http://creativecommons.org/licenses/by/4.0/

\begin{abstract}
Heavy infection of the virus leads to overproduction of cytokines. The overproduction of cytokine (cytokines storms) is responsible for the critical cases and deaths of COVID-19. The nuclear factor kappa-B stimulates the expression of the genes, which is responsible for cytokines storm and RNA transcription. The COVID-19 virus can be controlled by inhibition of nuclear factor kappa-B. Nuclear factor kappa-B is controlled by inhibition of hydrogen peroxide and inhibitor kappa-B kinase enzyme.
\end{abstract}

\section{Keywords}

Cytokine Storm, COVID-19, Nuclear Factor Kappa-B

\section{Introduction}

COVID-19 is a global epidemic disease that caused the death of more than three hundred thousand people. So far, there is still no effective treatment to end this crisis. This study is to track the symptoms of the disease and analyze the data of this disease to reach an acceptable pathological explanation to reach a solution to this crisis.

The core of this paper is tracking study of:

1) The critical cases as suffocation, and thrombosis.

2) The possibility of lung cells turning into cancer.

3) Transcription of virus and how to block it.

\section{Materials and Methods}

On 31 December 2019, a pneumonia outbreak was reported in Wuhan, China

[1]. The outbreak was traced to a novel strain of coronavirus [2], which was given the name 2019-Cov by the World Health Organization (WHO) [3] [4]. 
It was later renamed SARS-CoV-2 by the International Committee on Taxonomy of Viruses. As of 28 April 2020, there have been at least 213,824 confirmed deaths and more than 3,083,467 confirmed cases in the coronavirus pneumonia pandemic [5]. Coronaviruses are spherical, with club-shaped spikes that project from their surface, which in electron micrographs create an image like solar corona, from which their name derives and has RNA genome [6] [7]. Infection with the new coronavirus (severe acute respiratory syndrome coronavirus 2, or SARS-CoV-2) causes coronavirus disease 2019 (COVID-19).

The virus appears to spread easily among people, and more continues to be discovered over time about how it spreads. Data has shown that it spreads from person to person among those in close contact (within about 6 feet, or 2 meters). The virus spreads by respiratory droplets released when someone with the virus coughs, sneezes, or talks. These droplets can be inhaled or land in the mouth or nose of a person nearby. It can also spread if a person touches a surface with the virus on it and then touch his nose or eyes [8]. Although most people with COVID-19 have mild to moderate symptoms, the disease can cause severe medical complications and leads to death in some people. Older, adults, or people with existing chronic medical conditions are at greater risk of becoming seriously ill with COVID-19.

Based on all 72,314 cases of COVID-19 confirmed, suspected, and asymptomatic cases in China as of February 11, a paper by the Chinese CCDC released on February 17 and published in the Chinese Journal of Epidemiology has found that:

- $80.9 \%$ of infections are mild (with flu-like symptoms) and can recover at home.

- $13.8 \%$ are severe, developing severe diseases including pneumonia and shortness of breath.

- $4.7 \%$ as critical and can include respiratory failure, septic shock, and multi-organ failure.

- In about $2 \%$ of reported cases the virus is fatal.

- Risk of death increases in the older.

- Relatively few cases are seen among children [9].

The lungs are the organs most affected by COVID-19 because the virus accesses host cells via the enzyme angiotensin-converting enzyme (ACE2), which is most abundant in type II alveolar cells of the lungs [10].

The density of ACE2 in each tissue correlates with the severity of the disease in that tissue, some have suggested that decreasing ACE2 activity might be protective.

The virus also affects gastrointestinal organs as ACE2 is abundantly expressed in the gladder cells of gastric and duodenal [11].

ACE2 is present in the brain, with some reports of detection of the virus after cerebrospinal fluid assays although the presence of oligoclonal bands seems to be a common denominator in these patients [12].

ACE2 receptors are highly expressed in the heart and are involved in heart 
function.

Autopsies of people who died of COVID-19 have found diffuse alveolar damage and lymphocyte-containing inflammatory infiltrates within the lung [13].

Coronavirus uses a special surface glycoprotein called a "spike" to connect to ACE2 of type II alveolar cells of the lung and enter the host cell then multiplication and damage the cell and infect other cells and release cytokines.

Alveolar macrophages get activated by the interaction of toll-like receptors (TLR) present on the AM surface with the pathogen-associated molecular receptors (PAMP) present on the microbial cell. The interplay between TLRs and PAMPs transmits chemical signals that trigger the process of pathogen engulfment and the secretion of pro-inflammatory cytokines that enhance local immune response some progress to viral pneumonia, multi-organs failure, or cytokine storm [14].

Alveoli (singular: alveolus) are the site of gas exchange in the lung. Alveoli are thin-walled, sac-like structures lined by a single layer of flattened squamous epithelial cells: type I pneumocytes. This extremely thin nature of the type I pneumocytes facilitates gas exchange across their surface. The alveolar wall, or septum, consists of capillaries and minimal connective tissue support. As such, alveolar septal capillaries are almost in direct apposition with the type I pneumocyte. The type I pneumocyte and capillary lumen are separated only by the basement membrane of the type I pneumocytes, minimal or absent septal connective tissue, the basement membrane of the capillary endothelium, and the endothelial cells themselves. This provides an extremely narrow gap through which gases can diffuse, providing for efficient exchange of oxygen and carbon dioxide between alveolar spaces and capillaries.

In addition to the type I pneumocytes, alveoli also contain several additional cell types. Type II pneumocytes are cuboidal epithelial cells frequently residing in the corners of alveolar spaces. Type II pneumocytes are responsible for the secretion of surfactant. Surfactant is a fluid composed of phospholipids and proteins that coats the surface of alveolar spaces to reduce surface tension, allowing for alveoli to expand and remain open. In addition, type II pneumocytes play a crucial role in tissue repair in the lung. Following damage to type I pneumocytes, type II pneumocytes proliferate and differentiate into type I pneumocytes, thereby restoring the alveolar structure.

Finally, alveolar spaces contain a resident population of macrophages. Normally, alveolar macrophages are located in close apposition to type I pneumocytes and can be mistaken for type II pneumocytes. These macrophages, which are relatively low in number, readily phagocytize debris within alveoli, which can include surfactant, edema fluid, red blood cells, and pathogens (e.g. bacteria). Low numbers of macrophages are also normally present within the alveolar [15].

\subsection{Normal State of Lung}

During inhalation, the air loaded with oxygen enters into the air sac, and as the oxygen concentration is higher than the oxygen into blood capillary. The oxygen 
moves to the interstitial space then into blood capillary and loads on RBC.

On the other side, there are other red blood cells loaded with carbon dioxide at a higher concentration. So, the carbon dioxide moves to the air sac and then to outside with the exhale. The gas movement depends on concentration from high to low [16] (Figure 1).

\subsection{After Infection with COVID-19}

They observed many complications including accumulation of fluid in alveoli and pneumonia in lungs, respiratory failure, thrombosis in peripheral capillaries, heart problems, such as heart rhythm problems and a disease of the heart muscle that makes it hard for your heart to pump blood to the body (cardiomyopathy) and acute kidney injury [17].

\section{Results and Discussion}

During the early stages of virus infection, cytokines are produced when innate immune defenses are activated. One of the earliest cytokine produced is tumor necrosis factor-alpha (TNF- $\alpha$ ) which is synthesized by activated macrophages and monocytes. This cytokine changes nearby capillaries. So that circulating white blood cells can be easily brought to the site of infection. Neutrophils are one of the earliest types of phagocytic cells together with dendritic cells, and macrophages, enter a site of infection [18] [19].

Cytokines lead to vasodilatation and increase the permeability of blood vessels.

This allowing fluid and cells to leave the capillaries and enter into the alveoli and accumulation in it leading to difficulty in breathing,

\subsection{Cytokine Storm}

Heavy infection of the virus leads to overproduction of cytokines, the cytokines enter into capillaries and flow with bloodstream and reach to other peripheral capillaries. This leads to increase of capillaries permeability in different parts of the lung. This means that a large amount of fluid leaves the capillaries and accumulates in interstitial spaces and alveoli sac forming a pulmonary edema. This edema prevents oxygen moving from air sac to the blood capillaries leading to suffocation (Figure 2). Cytokine storm has occurred as a result of COVID-19 infection, While, the COVID-19-critical cases have occurred as a result of a Cytokine storm. In other words, cytokine is fuel of COVID-19.

In severe cases, people with pulmonary edema may need intensive or critical care. A machine will deliver oxygen under pressure to help get more air into the lung [20].

Cytokine storms might explain why some people have a severe reaction to coronavirus while others only experience mild symptoms. They could also be the reason why younger people are less affected, as their immune systems are less developed and so produce lower levels of inflammation-driving cytokines [21]. 


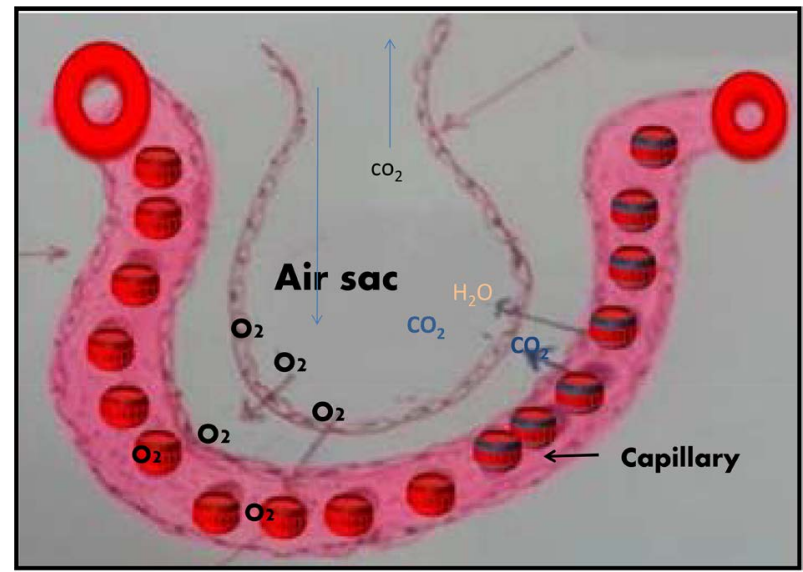

Figure 1. Shows the gas exchange in the alveoli.

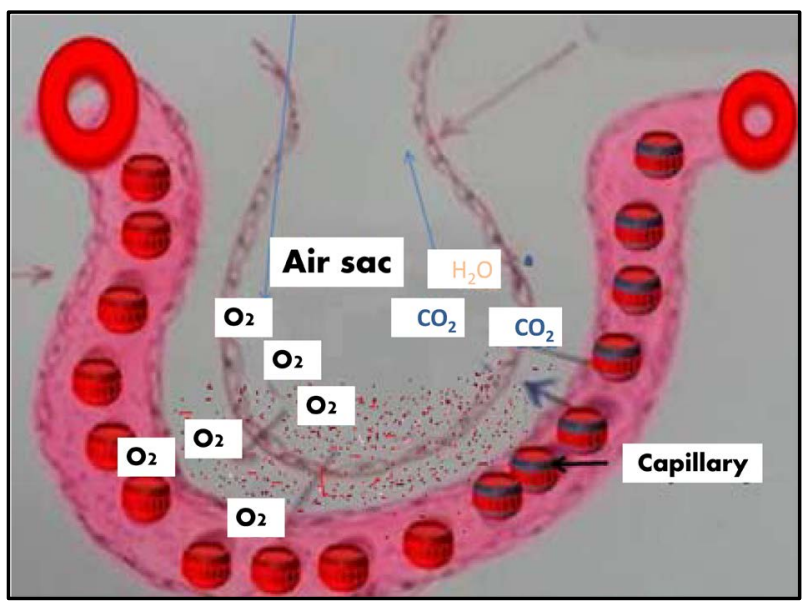

Figure 2. Shows the accumulation of fluid in the alveoli (pulmonary edema) due to cytokine storm.

\subsection{Clotting Formation}

When the fluid leaks from the blood vessel and accumulation in the interstitial space and air sac leads to suffocation. Leaking of the fluid from capillaries increases the viscosity of blood and lowing of blood content and its flow in these capillary. The lowering of blood flow in peripheral capillary results in formation of venous thrombi [22] [23]. In addition, increasing the viscosity of blood helps the formation of the thrombi in peripheral capillary [22] [23] [24]. Thus, cytokines storm leads to suffocation, and thrombosis in peripheral capillaries resulting in death.

In other words, the immune responses are attempting to counter the virus attack; they can end up by blocking oxygen uptake in the lungs.

\subsection{RNA-Transcription}

Virus expresses the production of GTPases. GTPases are a large family of hydrolase enzyme that binds to the Guanosine triphosphate, which specializes for the transport of RNA polymerase-II into the nucleus [25] [26]. 


\subsection{The Role of Nuclear Factor Kappa-B in COVID-19}

\subsubsection{The Role of Nuclear Factor Kappa-B in Formation of Cytokines Storm} The Cytokines production is controlled by genes (TNF- $\alpha$, IL-1 \& IL-6). These genes are expressed by activated nuclear factor kappa-B. This means that the continuous activation of nuclear factor kappa-B results in overproduction of cytokines (cytokines storm). The cytokines storm must be inhibited. To achieve that, we must keep the nuclear factor kappa-B in an inactive form [27].

\subsubsection{The Role of Nuclear Factor-Kappa-B in Cancer}

Nuclear factor kappa-B stimulates the expression of genes (Bcl-2 and muc-1) which is responsible for blocking the pathway of an intrinsic program of cell death. In addition, expression of genes (muc-4, muc-16, DcR3, and metalloproteinase enzyme) which is responsible for blocking the extrinsic programs of cell death, which lead to fleeing of cells from death. This converts the normal somatic cells to cancer cells [28] [29].

\subsubsection{The Role of Nuclear Factor Kappa-B in the Transcription of Coronavirus}

Nuclear factor kappa-B stimulates the expression of gene ARF-related protein-1 which expresses the production of GTPases [25]. GPN1/GPN2 defines a new family of small GTPase that is specialized for the transport of RNA polymerase-II into the nucleus [26]. RNA Polymerase-II (pol-II) (RNApII) is required for transcription of all messenger RNAs (mRNAs) as well as noncoding genes such as micro RNAs [30] [31] [32].

\section{Nuclear factor-kappa B (NF-Kb)}

The severity of the virus lies in the activation of the nuclear factor kappa-B. NF-kB stimulates the expression of several genes that produce cytokines which may lead to the cytokine storm, Cytokine storm leads to accumulating fluid into the air sacs of alveoli and leads to suffocation. In addition, NF-Kb expresses PAF Receptor1 (Platelet Activator receptor) which increases the possibility of formation thrombi in peripheral capillaries. As well as, it is responsible for the possibility of lung cells turning into cancer by expressing several genes responsible for shutting down the intrinsic and extrinsic programs of cell death. Moreover, NF-kB is responsible for the production of GTPase, which are specialized for the transport of RNA polymerase II into the nucleus, which plays a great role in transcription of mRNA of COVID-19 [25] [26] (Figure 3). Accordingly, in order to control the severity of the COVID-19 and prevent its transcription, we must control the activity of the nuclear factor-kappa B. As for the use of Chloroquine as a treatment of COVID-19 is a big mistake, it does not prevent the activity of the NF-Kb. On the contrary, Chloroquine activates the nuclear factor kappa-B [33].

In un-stimulated cells, both nuclear factor kappa $\mathrm{B}(\mathrm{NF}-\mathrm{Kb})$ and dynein light chain (LC8) bind with inhibitor kappa-B (IKB- $\alpha$ ) in the cytosol of the cell forming (NF-Kb, -IKB- $\alpha$, -LC8) complex. LC8 inhibits the activation of NF-Kb by interacting with IKB- $\alpha$, thereby, preventing its phosphorylation by IKK. 


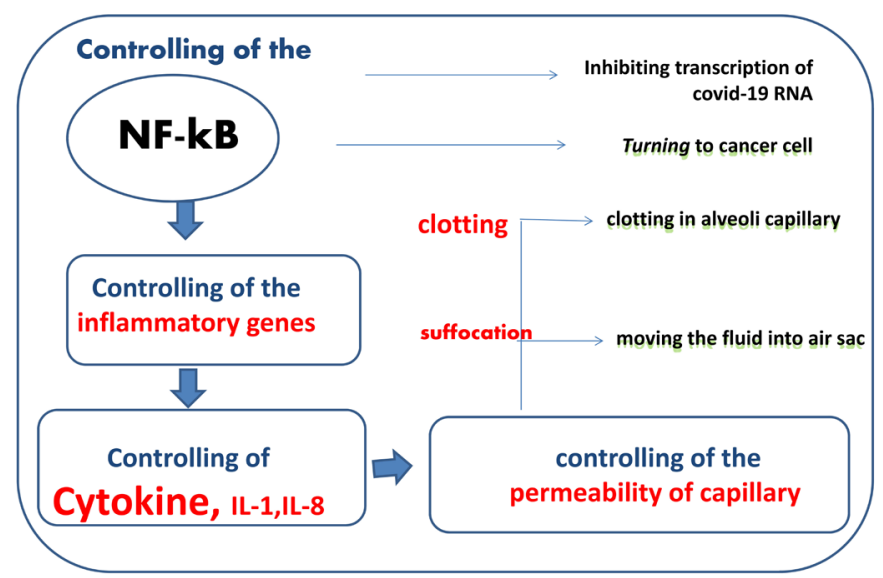

Figure 3. Shows the role of nuclear factor kappa-B in COVID-19.

When cells are exposed to $\mathrm{H}_{2} \mathrm{O}_{2}$, the LC8 forms a reversible intermolecular disulfide bond between the two Cys2 residues, leading to a conformational change that results in dissociation of LC8 from this complex, while IKB- $\alpha$ and $\mathrm{NF}-\mathrm{Kb}$ remain bound together [34]. Dissociation of LC8 from (NF-Kb, IKB- $\alpha$, and LC8) complex allows the IkB kinase enzyme (IKKs) to phosphorylate the inhibitor kappa-B (IKB- $\alpha$ ). This phosphorylation results in dissociation of IKB- $\alpha$ from NF-Kb.

Finally, NF-Kb becomes free and Trans locates into the nucleus and stimulates the expression of several genes including:

1) TNF- $\alpha$ gene which stimulates the production of cytokines. These cytokines reactivate the nuclear factor kappa-B by activating the kinase enzyme IKK, which phosphorylates IKB- $\alpha$ leading to establish a positive auto regulation loop that amplifies the inflammatory response and increase the duration of chronic inflammation and may lead to cytokines storm [18] [35].

2) Genes play a direct role in the shutdown of the intrinsic and extrinsic programs of cell death as (Muc-1, Muc-4, Muc-16-Bcl-2, MMPs, and Decoy-R3) leading to cancer.

3) Gene (ARF related protein-1) activates GTPase which plays a great role in the transcription of mRNA of the virus (Figure 4).

Therefore, to treat and stop the COVID-19, we have to prevent the activity of the nuclear factor kappa-B. We can do that by controlling the kinase enzyme (IKK) as well as, getting rid of the hydrogen peroxide and prevent new formation of it (Figure 5).

1) Controlling of kinase enzyme (IKK).

\section{By administrating Aspirin or Sulfasalazine}

Aspirin, the inhibitory effects of Aspirin and sodium salicylate result from the specific inhibition of ATP-binding to IKK $\beta$. Thus, IKK $\beta$-dependent phosphorylation of IkB- $\alpha$ is reduced preventing the activity of the NF-Kb pathway [36].

Sulfasalazine, it is a potent and specific inhibitor of the nuclear factor kappa-B activation [37]. 


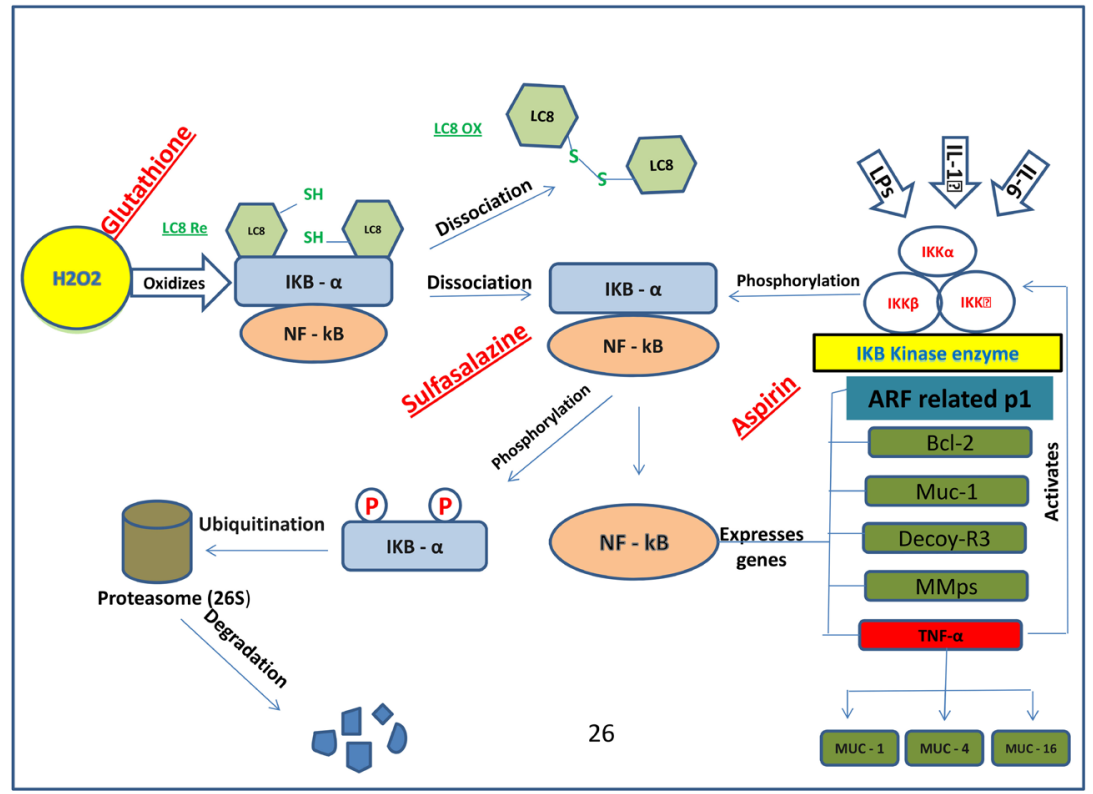

Figure 4. Shows $\mathrm{H}_{2} \mathrm{O}_{2}$ oxidizes the LC8 leading in dissociating it from IKB- $\alpha$, then IKKs phosphorylate the IKB- $\alpha$ resulting in free NF-Kb, which Trans locates into the nucleus and stimulates the expression of several genes which responsible for cytokine storm, shutdown the pathway of the intrinsic and extrinsic programs of cell death and transcription of mRNA of the virus.

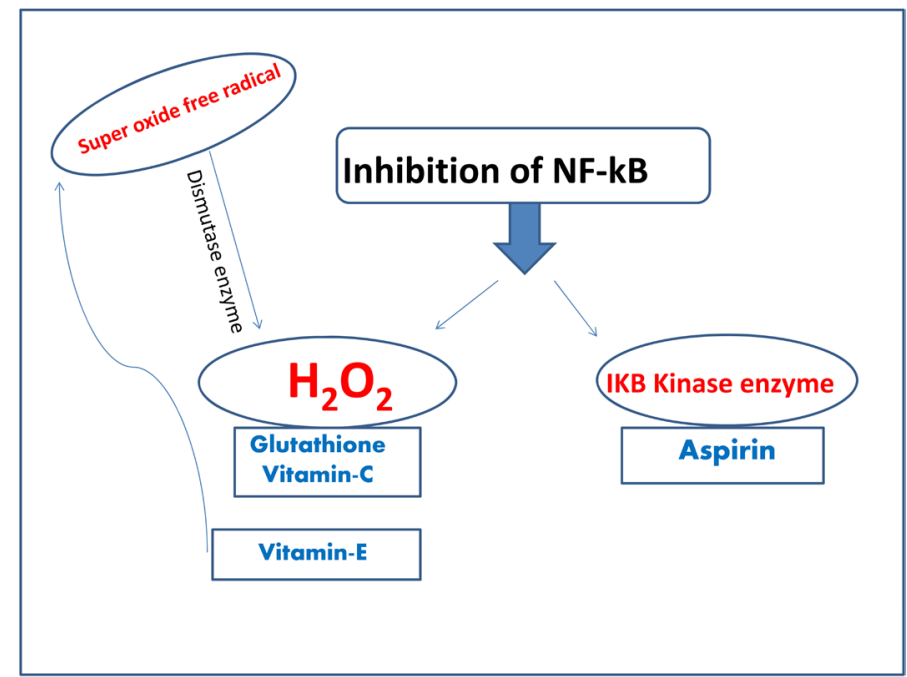

Figure 5. Shows the inhibition of nuclear factor kappa-B by blocking the activation of kinase enzyme of IKB, superoxide free radical, and hydrogen peroxide.

Sulfasalazine is as a direct inhibitor of IKK-alpha and -beta by antagonizing adenosine triphosphate binding but it has several side effects [38].

2) Getting rid of the hydrogen peroxide and preventing the new forma-

\section{tion of it.}

This is achieved by administration of glutathione, Vitamin-C, and Vitamin-E

The excessive amount of $\mathrm{H}_{2} \mathrm{O}_{2}$ is produced either directly as a byproduct of 
phase-I detoxification enzymes processing or indirectly by sodium dismutase enzyme which converts the superoxide free radical to $\mathrm{H}_{2} \mathrm{O}_{2}$. Hydrogen peroxide oxidizes the LC8 leading in dissociating it from IKB- $\alpha$ [33]. Glutathione is the most important antioxidant for neutralization of free radicals by donating its electron to $\mathrm{H}_{2} \mathrm{O}_{2}$ reduces it into $\mathrm{H}_{2} \mathrm{O}+\mathrm{O}_{2}$ [39].

Cysteine is the critical amino acid needed for the synthesis of glutathione (GSH). Vitamin B2, B3, B6, and Cysteine are needed for the production and maintenance of the active form of glutathione [40].

\section{a) Glutathione and catalase enzymes}

Glutathione and catalase enzymes convert hydrogen peroxide (activator of $\mathrm{NF}-\mathrm{Kb}$ ) to water and oxygen [41].

\section{b) Vitamin-C}

Vitamin- $\mathrm{C}$ is one of potent reducing agents and scavenger of free radicals in the biological systems, working as a scavenger of oxidizing free radicals and harmful oxygen-derived species, such a hydroxyl radical and hydrogen peroxide [42] [43].

c) Vitamin-E reduces the accumulation of superoxide radicals, so $\mathrm{H}_{2} \mathrm{O}_{2}$ formation is reduced. The recommended dose is $500 \mathrm{mg}$ three times daily [44] [45].

Finally, the proposed protocol to treat COVID-19 is as follows:

1) ASPIRIN $75 \mathrm{mg} /$ three-time daily

2) Glutathione $50 \mathrm{mg}$ three-times daily

3) Vitamin-C $500 \mathrm{mg} /$ three-time daily

4) Vitamin-E $500 \mathrm{mg} /$ three-time daily

\section{The scientific significance of this protocol:}

1) It prevents the occurrence of critical conditions associated with coronavirus such as inability to breathe and suffocation as well as cases of clotting in the peripheral capillaries.

2) A major key to treating cancer by returning the death cell programs of cancer cells to work again.

3) Preventing the coronavirus from transcription the Messenger RNA.

4) Preventing the expression of the production of the enzyme polymerase II. This may be a key to treating all RNA viruses by shutting off an animal virus.

\section{Proposed diet and treatment program of COVID-19 (Figure 6):}

\section{1) Glutathione}

The sources of glutathione are Broccoli, Tomato, Orange, lemon, apples, and grape. They contain sulforaphane which activates nuclear factor erythroid-2-related factor 2 (Nrf2). Nrf2 regulates the expression of genes encoding glutathione enzyme and antioxidant proteins [46] [47] [48].

2) Vitamin-C

The natural sources of vitamin-C are Oranges, Guava, and strawberries [48].

3) Vitamin-E

Sunflower seeds, peanuts, Avocado, Brazil nuts, and salmon fish [49]. 


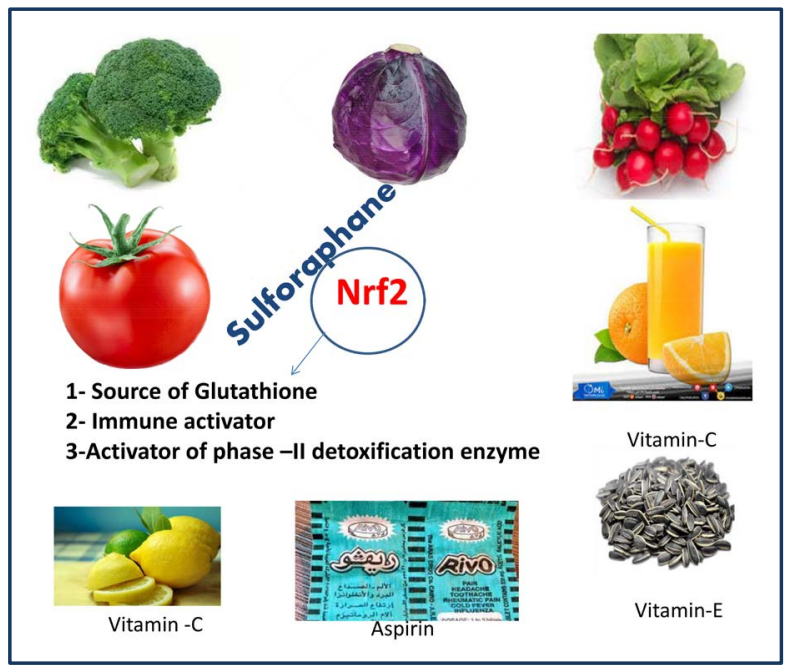

Figure 6. Shows the diet program for COVID-19 treatment.

\section{Conclusion}

Cytokines storm is responsible for critical cases and deaths of COVID-19. Activated nuclear factor kappa-B leads to cytokines storm formation. COVID-19 can be controlled by keeping the nuclear factor kappa-B in an inactive state.

\section{Acknowledgements}

Firstly, I wish to express sincere gratitude and deepest thanks to "ALLAH" who gave me everything I asked, and I were to count his divine favors, I would not be able.

Also, I would like to express my sincere cardinal to "ALLAH" Who guided me, pushed me, supported me and gave me the ability and patience to perform this work.

Secondly, I would like to thank Reham Ahmed Ibrahim, Microbiology specialist, Marine Microbiology Lab, National Institute of Oceanography and Fisheries (NIOF), Suez, Egypt for her supporting to perform this work.

Finally, I would like to thank Rasha Mohamed Mostafa, Computer Specialist, for her great assistance to me in presenting this research in it is current form.

\section{Conflicts of Interest}

The author declares no conflicts of interest regarding the publication of this paper.

\section{References}

[1] The Editorial Board (2020) Is the World Ready for the Coronavirus?-Distrust in Science and Institutions Could Be a Major Problem if the Outbreak Worsens. The New York Times.

[2] WHO Statement Regarding Cluster of Pneumonia Cases in Wuhan, China. http://www.who.int

[3] WHO (2020) Laboratory Testing of human Suspected Cases of Novel Coronavirus 
(nCoV) Infection: Interim Guidance, 10 January 2020. https://apps.who.int/iris/handle/10665/33037410

[4] Novel Coronavirus 2019, Wuhan, China. http://www.cdc.gov

[5] Coronavirus Disease (COVID-19): Outbreak Update-Canada.ca. https://www.canada.ca/en/public-health/services/diseases/2019-novel-coronavirus-i $\underline{\mathrm{nfe}}$

[6] De Groot, R.J., Baker, S.C., Baric, R., Enjuanes, L., Gorbalenya, A.E., Holmes, K.V., Perlman, S., Poon, L., Rottier, P.J., Talbot, P.J., Woo, P.C. and Ziebuhr, J. (2011) Family Coronaviridae. In: King, A.M., Lefkowitz, E., Adams, M.J., Carstens, E.B., International Committee on Taxonomy of Viruses, International Union of Microbiological Societies and Virology Division, Eds., Ninth Report of the International Committee on Taxonomy of Viruses, Elsevier, Oxford, 806-828.

[7] Almeida, J.D., Berry, D.M., Cunningham, C.H., Hamre, D., Hofstad, M.S., Mallucci, L., McIntosh, K. and Tyrrell, D.A. (1968) Virology: Coronaviruses. Nature, 220, 650. https://doi.org/10.1038/220650b0

[8] Neuman, B.W., Kiss, G., Kunding, A.H., Bhella, D., Baksh, M.F., Connelly, S., et al. (2011) A Structural Analysis of M Protein in Coronavirus Assembly and Morphology. Journal of Structural Biology, 174, 11-22. https://doi.org/10.1016/j.jsb.2010.11.021

[9] https://www.cdc.gov/coronavirus/2019-ncov/symptoms-testing/symptoms.html

[10] Charlton, C.L., Babady, E., Ginocchio, C.C., Hatchette, T.F., Jerris, R.C., Li, Y., et al. (2019) Practical Guidance for Clinical Microbiology Laboratories: Viruses Causing Acute Respiratory Tract Infections. Clinical Microbiology Reviews, 32, pii: e00042-18. https://doi.org/10.1128/CMR.00042-18

[11] Charlton, C.L., Babady, E., Ginocchio, C.C., et al. (2018) Practical Guidance for Clinical Microbiology Laboratories: Viruses Causing Acute Respiratory Tract Infections. American Society for Microbiology Journals. https://doi.org/10.1128/CMR.00042-18

[12] World Health Organization (2004) Summary of Probable SARS Cases with Onset of Illness from 1 November 2002 to 31 July 2003.

[13] Kelland, K. (2012) New Virus Not Spreading Easily between People: WHO. Reuters, London.

[14] Mehta, P., McCauley, D.F., Brown, M., Sanchez, E., Tattersall, R.S. and Manson, J.J. (2020) COVID-19: Consider Cytokine Storm Syndromes and Immunosuppression. The Lancet, 395, 1033-1034. https://doi.org/10.1016/S0140-6736(20)30628-0

[15] https://ohiostate.pressbooks.pub/vethisto/chapter/10-respiratory-tract-gas-exchange

[16] Wagner, P.D., Jones, J.H. and Longworth, K.E. (2015) Gas Exchange at Rest and during Exercise in Mammals. In: Parent, R.A., Ed., Comparative Biology of the Normal Lung, Second Edition, Elsevier, Amsterdam, 143-184.

[17] https://www.worldometers.info/coronavirus/coronavirus-symptoms/

[18] Thomas, P., Dash, P., Aldridge Jr., J., Ellebedy, A., Reynolds, C., Funk, A., Martin, W., Lamkanfi, M., Webby, R. and Boyd, K. (2009) The Intracellular Sensor NLRP3 Mediates Key Innate and Healing Responses to Influenza A Virus via the Regulation of Caspase-1. Immunity, 30, 566-575. https://doi.org/10.1016/j.immuni.2009.02.006

[19] Ting, J. (2009) The NLRP3 Inflammasome Mediates in Vivo Innate Immunity to Influenza A Virus through Recognition of Viral RNA. Immunity, 30, 556-565. https://doi.org/10.1016/j.immuni.2009.02.005

[20] https://www.healthline.com/health/pulmonary-edema 
[21] https://www.newscientist.com/article/2237259-why-dont-children-seem-to-get-very -ill-from-the-coronavirus/\#ixzz6LE2kokxU

[22] Smith, B.D. and La Celle, P.L. (1982) Blood Viscosity and Thrombosis: Clinical Considerations. Progress in Hemostasis and Thrombosis, 6, 179-201. https://www.ncbi.nlm.nih.gov/pubmed/6762612

[23] Güneş, H. and Kirişci, M. (2018) The Relationship between Whole Blood Viscosity and Deep Vein Thrombosis. Turkiye Klinikleri Cardiovascular Sciences, 30, 6-12.

[24] https://www.newscientist.com/term/cytokine-storm/\#ixzz6KkzNZl5j

[25] http://www.bu.edu/nf-kb/gene-resources/target-genes

[26] Carre, C. and Shiekhattar, R. (2011) Human GTPase Associate with RNA Polymerase II to Mediate Its Nuclear Import. Molecular and Cellular Biology, 31, 3953-3962. https://doi.org/10.1128/MCB.05442-11

[27] NF- $\kappa$ B Target Genes. Target Genes of NF- $\kappa$ B. Cytokines/Chemokines and Their Modulators Immunoreceptors Proteins Involved in Antigen. https://www.bu.edu/nf-kb/gene-resources/target-genes/7

[28] El-Khodary, M.S.M. (2018) Quranic Verse No. 8 of Surat Al-Jumu'ah Describes Cancer as a Complete and Accurate Description and Leads Us to Determine the True Cause of Cancer (Part-I). CellBio, 7, 1-11. https://doi.org/10.4236/cellbio.2018.71001

[29] El-Khodary, M.S.M. (2018) Quranic Verse No. 8 of Surat Al-Jumu'ah Leads Us to Describe Cancer and Determine Its True Cause (Part-II). CellBio, 6, 13-22. https://doi.org/10.4236/cellbio.2018.82002

[30] Armache, K.J., Kettenberger, H. and Cramer, P. (2003) Architecture of Initiation-Competent 12-Subunit RNA Polymerase II. Proceedings of the National Academy of Sciences of the United States of America, 100, 6964-6968. https://doi.org/10.1073/pnas.1030608100

[31] Bushnell, D.A. and Kornberg, R.D. (2003) Complete, 12-Subunit RNA Polymerase II at 4.1- $\AA$ Resolution: Implications for the Initiation of Transcription. Proceedings of the National Academy of Sciences of the United States of America, 100, 6969-6973. https://doi.org/10.1073/pnas.1130601100

[32] Young, R.A. (1991) RNA Polymerase II. Annual Review of Biochemistry, 60, 689-715. https://doi.org/10.1146/annurev.bi.60.070191.003353

[33] Park, J., Kwon, D., Choi, C., Oh, J.-W. and Benveniste, E.N. (2003) Chloroquine Induces Activation of Nuclear Factor-kappaB and Subsequent Expression of Pro-Inflammatory Cytokines by Human Astroglial Cells. Journal of Neurochemistry, 84, 1266-1274. https://doi.org/10.1046/j.1471-4159.2003.01623.x

[34] Jung, Y., Kim, H., Min, S.H., Rhee, S.G. and Jeong, W. (2008) Dynein Light Chain LC8 Negatively Regulates NF- $\kappa$ b through the Redox-Dependent Interaction with IKB- $\alpha$. The Journal of Biological Chemistry, 283, 23863-23871.

[35] Yamamoto, Y. and Gaynor, R.B. (2001) Therapeutic Potential of Inhibition of NF- $\kappa$ b Pathway in the Treatment of Inflammation and Cancer. The Journal of Clinical Investigation, 107, 135-142.

[36] Yin, M.J., Yamamoto, Y. and Gaynor, R.B. (1998) The Anti-Inflammatory Agent Aspirin and Salicylate Inhibitor the Activity of I $\kappa$ B Kinase- $\beta$. Nature, 396, 77-80. https://doi.org/10.1038/23948

[37] Wahl, C., Liptay, S., Adler, G. and Schmid, R.M. (1998) Sulfasalazine: A Potent and Specific Inhibitor of Nuclear Factor-kappaB. Journal of Clinical Investigation, 101, 1163-1174. https://doi.org/10.1172/JCI992 
[38] Weber, C.K., Liptay, S., Wirth, T., Adler, G. and Schmid, R.M. (2000) Suppression of NF-kappaB Activity by Sulfasalazine Is Mediated by Direct Inhibition of IkappaB Kinases Alpha and Beta. Gastroenterology, 119, 1209-1218. https://doi.org/10.1053/gast.2000.19458

[39] Irshad, M. and Chaudhuri, P.S. (2002) Oxidant-Antioxidant System: Role and Significance in Human Body. Indian Journal of Experimental Biology, 40, 1233-1239.

[40] Schreck, R., Rieber, P. and Baeuerle, P.A. (1991) Reactive Oxygen Intermediates as Apparently Widely Used Messengers in the Activation of the NF-kappaB Transcription Factor and HIV-1. The EMBO Journal, 10, 2247-2258.

[41] Sheng, Y., Abreu, I.A., Cabelli, D.E., Maroney, M.J., Miller, A., Teixeiera, M. and Valentine, J.S. (2014) Superoxide Dismutases and Superoxide Reductases. Chemical Reviews, 114, 3854-3918.

[42] Hacisevki, A. (2009) An Overview of Ascorbic Acid Biochemistry. Journal of Faculty of Pharmacy, 38, 233-255. https://doi.org/10.1501/Eczfak_0000000528

[43] Arrigoni, O. and DeTullio, M.C. (2002) Ascorbic Acid: Much More than Just Antioxidants. Biochimica et Biophysica Acta, 1569, 1-9.

https://doi.org/10.1016/S0304-4165(01)00235-5

[44] Kagan, V.E., Kisin, E.R., Kawai, K., et al. (2002) Towards Mechanism-Based Antioxidant Interventions. Annals of the New York Academy of Sciences, 959, 188-198.

[45] Packer, L. and Ong, A.S.H. (1998) Biological Oxidants and Antioxidants: Molecular Mechanisms and Health Effects. AOCS Press, Champaign.

[46] https://www.myhdiet.com/healthnews/ampm/natural-sources-glutathione

[47] Steele, M.L., Fuller, S., Patel, M., Kersaitis, C., Ooi, L. and Münch, G. (2013) Effect of Nrf2 Activators on Release of Glutathione, Cysteinylglycine and Homocysteine by Human U373 Astroglial Cells. Redox Biology, 1, 441-445. https://doi.org/10.1016/j.redox.2013.08.006

[48] http://www.foodmatters.com/article/10-of-the-top-natural-sources-of-vitamin-c

[49] https://www.healthline.com/nutrition/foods-high-in-vitamin-e 